\title{
Bernardo Guimarães e o Prólogo às Folhas do Outono ${ }^{1}$
}

\author{
Sergio Alves Peixoto \\ Universidade Federal de Minas Gerais
}

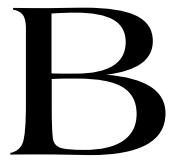

ernardo Guimarães deveria estar bastante irritado, quando resolveu escrever o Prólogo a seu último livro de poemas, Folhas do Outono, publicado em $1883 .^{2}$ Em meio às tradicionais tiradas de modéstia afetada, seu prólogo é bastante ferrenho, dispondose o autor a mostrar como um certo tipo de poesia feita no Brasil à sua época andava mal das pernas, tanto no que diz respeito ao conteúdo, quanto à forma. A partir de uma comparação de seu modesto texto com o famosíssimo prólogo ao Cromwel, de Victor Hugo, com os prefácios de Castilho e com os pós-escritos que José de Alencar escreveu para determinados de seus romances, Bernardo confessa o motivo principal que o levou a escrever seu texto introdutório:

Não tenho por costume escrever prólogos ou preâmbulos, precedendo as poucas e fracas produções literárias que até aqui tenho entregado à luz da publicidade. Entendo que as explicações, que aí se podem dar, as reflexões, que aí se expendem, não lhes podem atenuar os defeitos, nem realçar o mérito, que porventura tenham.

É verdade que um bom prólogo constitui às vezes por si só uma obra magistral, como são, por exemplo, o prólogo do Cromwel de Victor Hugo, alguns prefácios do visconde de Castilho, e os poscritos de José de Alencar, que são incontestavelmente de grande valor literário e filológico. Eu porém não pretendo e nem posso fazer outro tanto ao entregar ao público esta pequena coleção de poesias; mas veio-me a vontade, e me é talvez necessário por esta vez conversar um pouco com o leitor, se ele estiver por isso. (p.327)

\footnotetext{
${ }^{1}$ Uma versão deste artigo foi publicada anteriormente, em forma de CD Rom, na Revista Acervos Literários, v. 2, n. 1, da UFOP.

${ }^{2}$ GUIMARÃES, 1959.
} 
Conversar com o leitor, sim, mas não só e exclusivamente isso: conversar e convencer esse leitor que se confunde com românticos desavisados e com poetas e críticos que estavam se deixando influenciar por uma poesia e uma crítica que vinham de fora, e às quais deveriam se submeter sem qualquer questionamento, no intuito de ficarem, segundo Bernardo, dentro da moda e não, pelo contrário, atentos às reais necessidades de um país que se queria independente política e culturalmente.

Assim é que se dirige, com certeza bastante ironicamente, ao "amabilíssimo e paciente leitor" para falar da importação de modas poéticas a que assistia cotidianamente:

Em primeiro lugar, cumpre-me pedir desculpa ao amabilíssimo e pacientíssimo leitor por não poder eu acompanhar em tudo a moderna escola poética, hoje em voga no Brasil por importação. Creio, que é uma importação que em vez de melhorar, estraga e desvaira a índole da inspira;cão nacional. Não posso compreendê-la, e por isso não posso acompanhá-la.

Não posso compreender o que seja uma escola literária que se subjuga a um sistema crítico-filosófico, histórico-filológico-etnográficosociológico, etc., etc.

É querer amarrar o leviano, gracioso e independente batel da inspiração ao reboque da pesada charrua da crítica moderna, tão cheia de teorias sibilinas, e ainda mais carregada de erudição que a antiga. (p.327)

Não há dúvida alguma de que seu alvo principal, no que diz respeito à crítica, é Sílvio Romero, o mais influente crítico de sua época, defensor ardente de uma filosofia, de uma crítica e de uma poesia positivistas, que grassavam na França, frutos do pensamento de um importante filósofo da época: Augusto Comte. Segundo Comte, no seu Catecismo Positivista ${ }^{3}$, o objetivo da crítica e da nova literatura que surgia devia-se basear primordialmente na razão. No também famoso prefácio a este livro, o filósofo francês expõe suas teses revolucionárias para a época, principalmente a de que a derrocada do mundo romântico estava instalada, e que o dado subjetivo deveria, daquele momento em diante, ser subordinado ao objetivo. Para ele a submissão do mundo interior ao exterior é verdade essencial e, a partir dela, instaura-se uma hierarquia

${ }^{3}$ COMTE, 1973. 
na qual o elemento subjetivo jamais é anulado, mas - e isto sim devidamente colocado em seu 'positivo' lugar:

A principal força de nossa razão consiste[...]em subordinar suficientemente o subjetivo ao objetivo, para que nossas operações interiores possam representar o mundo exterior com o predomínio imutável que a este pertence.

[...]sempre havemos de precisar de uma certa disciplina para conter no grau conveniente nossa disposição espontânea a substituir exageradamente o interior ao exterior.[...] (p.144)

Já em 1878, Ślvio Romero, havia passado o atestado de óbito ao Romantismo, resumindo-o, meramente, a um "cadáver, e pouco conhecido". ${ }^{4}$ Bernardo de forma alguma concorda com essa opinião e ataca veementemente toda aquela importação que via chegar da França: no Brasil, ela não poderia medrar vigorosamente, pois o solo brasileiro e o momento nacional eram outros, nossa índole tinha particularidades próprias e exclusivas. Foi Sílvio Romero, melhor do que ninguém, quem conseguiu traçar um panorama sucinto da poesia e da literatura em geral que se fazia na Europa e em nosso país. Tanto o Parnasianismo quanto a poesia científica, ambos exemplos da aliança da objetividade com a razão, e devedores, portanto, do que o Positivismo de Comte e de Sílvio Romero pregavam, não conseguiram, entretanto, encobrir a complexidade do momento. Paralelamente a esse tipo de poesia, surgiam os baudelairianos, os decadentes, os simbolistas e muitos outros. É no prefácio intitulado "A poesia de hoje", de seu livro pretensamente revolucionário em matéria de poesia, os Cantos do fim do século ${ }^{5}$, que Sílvio delineia sua época, não sabendo muito bem o que fazer com tantos "ismos" que invadiam o panorama da literatura brasileira e perturbavam a sua razão tão pretensamente condutora de si mesma e de tudo. Na realidade Sílvio Romero não sabia o que fazer com ela em face de textos e de propostas tão diferentes do que ele almejava para uma poesia brasileira racional que se gabava de ter posto por terra o, para ele, ultrapassado Romantismo. A luta de Comte, na Europa, e de Sílvio Romero, no Brasil, parecia uma luta inglória. A razão não tinha conseguido superar as diversas subjetividades e a literatura se fazia, entre outras coisas, de imaginação e de fantasias:

\footnotetext{
${ }^{4}$ ROMERO, 1878. p. XI.

${ }^{5}$ ROMERO, 1878. p. XI.
} 
Satanistas, cientificistas, socialistas, pessimistas, parnasianos, impressionistas, simbolistas, decadentes, realistas, naturalistas, cerrados batalhões de toda essa gente tem talado os campos onde alardeou grandezas o velho romantismo. ${ }^{6}$

Deixemos, porém, Sílvio Romero e seus seguidores de lado e dediquemo-nos, mais especificamente ao prólogo de Bernardo Guimarães. Pouco a pouco, o poeta põe em xeque as novidades que ele vê chegarem da Europa, principalmente, é claro, da França comtiana. Os jovens e talentosos escritores do Brasil começam a se deixar envolver por todo um aparato crítico-filosófico que acaba, malfadadamente, retirando deles toda a capacidade imaginativa e mesmo uma certa dose de nacionalismo, sempre defendido por Bernardo em seu prólogo. Entre uma arte inspirada, eivada de nacionalismo, e uma poesia fria e raquítica que, segundo ele, só pode brotar de um solo influenciado pelas teorias positivistas, Bernardo fica, naturalmente com a primeira.

A moderna crítica literária - principalmente no Brasil, onde ela, em meu entender é inteiramente descabida, - atrelada ao carro da filosofia positivista, que hoje predomina, e identificando-se com ela, pretende cortar as asas à inspiração, vedar-lhe o espaço livre, e obrigá-la a arrastar-se fatalmente por uma senda por ela cientificamente demarcada.

Está no gosto deste século do vapor, das vias férreas, e da febre do progresso material, e constitui uma espécie de engenharia literária, marcando rumos e nivelamentos, e assentando trilhos, pelos quais têm de rodar irremissivelmente as musas de todos os poetas, à maneira de vagões arrastados pela locomotiva.

Parece-me, contudo, que esse sistema crítico-filosófico-positivista o mais que pode conseguir é abafar, ou amesquinhar a inspira;cão, suprimir mesmo a poesia, mas nunca criar, nem mesmo dirigir a nascente literatura de uma nacionalidade nova. Se alguma coisa dela pode resultar, será uma literatura fria e raquítica, factícia e convencional, que poderá constituir um oficio, mas nunca uma arte verdadeiramente inspirada e criadora.

Creio que os poetas brasileiros, nascidos no seio de uma pátria nova e cheia de seiva juvenil, não devem ter os olhos incessantemente fixos nas freqüentes evoluções das literaturas cansadas das nações do velho mundo. (p.328)

\footnotetext{
${ }^{6}$ ROMERO, 1980. p. 1632.
} 
Mais adiante, Bernardo confessa que sua bandeira é a liberdade, palavra chave para o período romântico. Assim como Gonçalves Dias, em seu prefácio aos Primeiros cantos disse que tinha adotado "todos os ritmos da metrificação portuguesa e [usado] deles como [lhe] pareceram quadrar melhor com o que [ele] pretendia exprimir"”, Bernardo Guimarães tem também como pressuposto primordial a liberdade para o artista romântico. Assim é que acaba confessando:

No meu entender, o que se chama escola realista, com mais propriedade se deve chamar um gênero a que qualquer pode se entregar, uma vez que se sinta com pendor e aptidão para ele. Porém é o maior dos absurdos querer inculcá-lo como a última, a única, a mais perfeita manifestação do belo em literatura.

Mas não devo ocupar por mais tempo a atenção do leitor com uma questão que exige longos desenvolvimentos e não cabe portanto nos limites de um prólogo a um limitado número de poesias de bem pouco valor. Aventurando estas reflexões, é meu único propósito exibir minha profissão de fé em literatura, declarando que sou eclético, isto é, que sigo todas as escolas, ou por outra, que não sigo escola alguma.

Por isso não se me vá atribuir a ambiciosa pretensão de querer passar por um gênio criador, por chefe de escola, abrindo novos horizontes, explorando minas desconhecidas e fazendo o batel da inspiração vogar "Por mares nunca dantes navegados".

Pelo contrário, procuro moldar minhas fracas produções pelos melhores tipos da arte quer antiga, quer moderna. Somente procuro não ser imitador servil de nenhum deles. (p.329-330)

Aqui terminam as palavras de Bernardo Guimarães, no que diz respeito ao primeiro momento de seu prólogo. Agora, é sobre a forma que ele vai falar, mais especificamente sobre o emprego desabusado do verso alexandrino pela maioria de nossos poetas de então, verso que ele se recusou veementemente a usar. Para Bernardo, o alexandrino é sem melodia, monótono, cansativo para os ouvidos brasileiros:

Quero falar do verso alexandrino, hoje tão em voga, de preferência a outro qualquer metro. [...] Já não se diz - fazer versos - mas sim - fazer alexandrinos. [...] Aos antigos e variadíssimos metros tão vantajosamente usados na poesia portuguesa, vai-se substituindo o

7 DIAS, 1959. p. 101. 
predomínio quase exclusivo do verso alexandrino [...] o metro das palavras balofas e retumbantes; dos plurais enfáticos - como eternidades - imensidades; das sinonímias intermináveis, metro que reclama, não por necessidade ou elegância, mas para encher medida, o emprego da conjunção $e$ a cada passo; metro enfim de incontestável monotonia. [...]

$\mathrm{O}$ alexandrino não dispensa a rima. Sem ela e às vezes mesmo com ela quase se confunde com a prosa. [...] Se o consoante no alexandrino é atrelado dois a dois, é de uma monotonia abominável; se distancia-se um pouco, a rima torna-se quase insensível e, portanto de muito fraco efeito.

O alexandrino [...] com sua pesada monotonia e inflexibilidade, tornase quase absolutamente refratário à onomatopéia, sem a qual não há verso nem harmonia nem melodia. [...] O verso pode estar construído com irrepreensível correção; mas se não contém ao menos uma daquelas qualidades, é verso sem poesia, ou por outra, é prosa em verso. (p.330-331)

Bernardo não chega a dizer que o alexandrino deva ser expurgado da poesia brasileira. Acha mesmo que ele deve, quando realmente necessário, ser usado, mas sempre "com muita parcimônia, ou intercalado com outros ritmos, [pois] manejado por mãos habilíssimas pode produzir bom efeito". ${ }^{8}$ Exemplos de bons alexandrinos, principalmente em latim e em francês, línguas às quais ele se adequaria perfeitamente são, então, dados ao leitor, e Bernardo dá por encerrado este assunto.

Tendo já comentado sobre o fundo e a forma dessa poesia que tanto critica, parecia-nos que o prólogo tinha-se esgotado. Entretanto, Bernardo começa a falar de um outro motivo que gostaria de ver discutido em seu texto, um motivo bastante pessoal. Em um jornal da Corte, Valentim Magalhães, falando sobre outro poeta das Minas Gerais - Augusto de Lima - diz o seguinte:

Deve orgulhar-se nele ( Augusto de Lima) a província de Minas, cujo maior poeta, outrora tão ardido e fecundo, hoje se esteriliza numa apatia mórbida, donde só rebentam monótonas cantilenas em honra de César." (p.334)

Valentim Magalhães estava se referindo a dois poemas dedicados a D. Pedro II, quando de sua visita a Ouro Preto e, como Bernardo

${ }^{8}$ GUIMARÃES, 1959. p. 330. 
desconhecia outro poeta que tivesse escrito, para aquele momento, alguma coisa em homenagem ao Imperador, toma para si as palavras de Valentim Magalhães, desculpando-se pela monotonia de seus textos. Afinal de contas, segundo ele, os poemas tinham sido produzidos às pressas, em meio às comemorações da visita de tão nobre personagem à sua cidade. Confessa, então, tê-las modificado e melhorado. Assim, o Império ficou melhor servido e Valentim Magalhães, a quem ele diz prezar muito, mudaria, necessariamente de opinião:

Que essas cantilenas - apenas duas - são monótonas, eu o reconheço, e até mesmo mal feitas, porque foram quase improvisadas no meio do tumulto e ruído das festas. Mas agora ao editá-las de novo na presente coleção, tomei o cuidado de corrigi-las e melhorá-las, - não sei se o consegui, - a fim de torná-las mais dignas dos altos personagens, a quem são dirigidas, e mais merecedoras da indulgência do Sr. Valentim Magalhães, cujo alto critério e ilustração muito respeito. (p.334)

Com isso, o prólogo se encerra. Sua importância principal, acreditamos, é ter ele demonstrado como Bernardo Guimarães foi um poeta romântico, no bom sentido do termo, isto é, um poeta preocupado com seu trabalho e com os problemas que a poesia da época lhe apresentava. Um romântico bem consciente de seu lugar dentro da poesia brasileira que tanto defendeu, como nos mostra muito bem o prólogo que agora acabamos de comentar.

\section{Referências Bibliográficas}

COMTE, Augusto. Curso de filosofia positivista; O espírito positivo; Catecismo positivista. São Paulo: Abril, 1973. (Coleção Os pensadores, XXXIII)

DIAS, Gonçalves. Poesia completa e prosa escolbida. Rio de Janeiro:Aguilar, 1959.

GUIMARÃES, Bernardo. Poesias completas de Bernardo Guimarães. Rio de Janeiro: INL, 1959.

ROMERO, Sílvio. Cantos do fim do século. Rio de Janeiro: Tipografia Fluminense, 1878.

ROMERO, Sílvio. História da literatura brasileira. Rio de Janeiro: José Olímpio, 1980. 


\section{Resumo}

Este artigo mostra como o poeta romântico Bernardo Guimarães via a poesia de sua época e as novidades que chegavam da França, buscando realçar sua posição acirrada no que diz respeito à influência do Positivismo de Comte na poesia romântica que ainda se praticava no Brasil.

\section{Résumé}

Cet article montre la position du poète romantique Bernardo Guimarães sur la poésie de son époque e les nouveautés françaises, en cherchant souligner sa position critique face à l'influence du Positivisme de Comte sur la poésie romantique brésilienne. 